Check for updates

Cite this: RSC Adv., 2018, 8, 37176

Received 18th August 2018

Accepted 22nd October 2018

DOI: $10.1039 / \mathrm{c} 8 \mathrm{ra06908e}$

rsc.li/rsc-advances

\section{Green synthesis of bio-molecule encapsulated magnetic silver nanoparticles and their antibacterial activity}

\author{
A. K. M. Atique Ullah, (D) ${ }^{\star a b}$ M. F. Kabir, ${ }^{c}$ M. Akter, ${ }^{d}$ A. N. Tamanna, ${ }^{C}$ A. Hossain, ${ }^{e}$ \\ A. R. M. Tareq, ${ }^{\text {ab }}$ M. N. I. Khan, ${ }^{\text {af }}$ A. K. M. Fazle Kibria, ${ }^{\text {ag }}{ }^{\text {Masaaki Kurasaki }}{ }^{d}$ \\ and M. M. Rahman*c
}

Persuaded by the necessity of finding new sources of antibiotics, silver nanoparticles (Ag NPs) were synthesized by adopting a newly developed green synthesis technique and subsequently, their antibacterial activity against different pathogenic bacteria was evaluated. We have successfully synthesized bio-molecule capped ferromagnetic Ag NPs with an average crystallite size of $13 \mathrm{~nm}$ using $\mathrm{AgNO}_{3}$ solution as a precursor and Artocarpus heterophyllus leaf extract as a reducing and capping agent. The characterization of the synthesized Ag NPs was carried out using various techniques such as UV-visible (UV-Vis) spectroscopy, energy dispersive X-ray (EDX) spectroscopy, Fourier transform infrared (FT-IR) spectroscopy, field emission scanning electron microscopy (FESEM), transmission electron microscopy (TEM), thermogravimetry (TG), and vibrating sample magnetometer (VSM) analyses. After exposing the synthesized Ag NPs to two Gram-positive bacteria - Staphylococcus aureus and Bacillus cereus and two Gram-negative bacteria - Escherichia coli and Salmonella typhimurium, the zones of inhibition were found to be $15,16,19$, and $18 \mathrm{~mm}$, respectively. These results imply that the Artocarpus heterophyllus leaf extract mediated green synthesized bio-molecules encapsulated Ag NPs can be considered as a potential antibiotic against human pathogens which is very encouraging.

\section{Introduction}

Susceptible microorganisms in the human body are becoming resistant to the available chemical antibiotics, which is a serious public health concern. ${ }^{1}$ To get rid of from such an unwanted situation, investigations into the development of new and effective antimicrobial agents from new precursors are going on worldwide. A recent remedial target is nanomaterials with antibacterial capability, such as silver nanoparticles (Ag NPs). The antibacterial potentiality of Ag NPs in wound healing is well

${ }^{a}$ Nanoscience and Technology Research Laboratory, Atomic Energy Centre, Bangladesh Atomic Energy Commission, Dhaka 1000, Bangladesh. E-mail: atique.chem@gmail. com

${ }^{b}$ Chemistry Division, Atomic Energy Centre, Bangladesh Atomic Energy Commission, Dhaka 1000, Bangladesh

'Department of Physics, University of Dhaka, Dhaka 1000, Bangladesh. E-mail: mmizanurr@hotmail.com

${ }^{d}$ Graduate School of Environmental Science, Hokkaido University, 060-0810 Sapporo, Japan

${ }^{e}$ Department of Physical and Inorganic Chemistry, Institute of Natural Sciences and Mathematics, Ural Federal University, 620000 Yekaterinburg, Russia

${ }^{f}$ Materials Science Division, Atomic Energy Centre, Bangladesh Atomic Energy Commission, Dhaka 1000, Bangladesh

${ }^{g}$ Nuclear Safety, Security and Safeguards Division, Bangladesh Atomic Energy Commission, Dhaka 1207, Bangladesh established. ${ }^{2}$ Moreover, because of the unique property of Ag NPs against microorganisms, they are in high demand in consumer products such as medicine and medicinal devices, foodstuffs, cleaning agents, and clothing. ${ }^{3-5}$ Recently, it has been reported that magnetic NPs are more effective for biomedical applications, especially for antibacterial and antifungal purposes. ${ }^{6}$ Thus, the synthesis of magnetic Ag NPs would be a great achievement in biomedical applications, especially in the field of antibacterial activity.

The usual chemical synthesis process of Ag NPs is the reduction of silver ions in solution media or at high temperatures in a gaseous environment. ${ }^{7}$ Sodium borohydride, a wellaccepted reducing agent, is used for silver ion reduction and polyvinyl alcohol or gelatine is applied as a capping agent. ${ }^{\mathbf{8}}$ These chemicals increase unwanted environmental toxicity and biological hazards. ${ }^{7}$ Moreover, the application of high temperatures badly impacts on the cost of the synthesis process. Therefore, research and development of a suitable route for the synthesis of Ag NPs without using non-toxic reagents which is relatively cost-effective is of great interest. Green synthesis methods using leaf extract as the source of both the reducing and capping agents might be a potential candidate for the synthesis of Ag NPs. It has been reported that noble metals (e.g., gold) although diamagnetic in bulk states become magnetic when coated with organic molecules such as thiols and amine 
derivatives. ${ }^{\mathbf{9} 10}$ Therefore, it can be speculated that the presence of biomolecules in the leaf extract might contribute to producing magnetic Ag NPs.

Reports on the green synthesis of Ag NPs using a leaf extract of Eucalyptus hybrid, ${ }^{\mathbf{1 1}}$ Syzygium cumini, ${ }^{\mathbf{1 2}}$ Sesuvium portulacastrum ${ }^{13}$ Boswellia ovalifoliolata, ${ }^{\mathbf{1 4}}$ Calotropis procera, ${ }^{\mathbf{1 5}}$ Musa paradisiacal, ${ }^{\mathbf{1 6}}$ Acalypha indica,${ }^{\mathbf{1 7}}$ and Cinnamon zeylanicum ${ }^{\mathbf{1 8}}$ are available. Not only metallic Ag NPs but also homologous materials such as $\alpha-\mathrm{Bi}_{2} \mathrm{O}_{3}$ microflowers/novel $\gamma-\mathrm{Bi}_{2} \mathrm{O}_{3}$ microspindles, ${ }^{19}$ natural groundnut shell biowaste derived nano carbons, ${ }^{20}$ silver-silica nanocomposites, ${ }^{21} \mathrm{Ag}_{2} \mathrm{~S}$ nanoparticles, colloidal solutions ${ }^{22}$ etc. are currently used for their antibacterial activity. To the best of our knowledge, there is no report available on the synthesis of Ag NPs using Artocarpus heterophyllus leaf extract. This leaf extract consists of several biomolecules, such as sapogenins, cycloartenone, cycloartenol, $\beta$ sitosterol, and tannins. ${ }^{23}$ Artocarpus heterophyllus, commonly known as jackfruit, a famous fruit variety in Bangladesh, is an angiosperm, belonging to the Moraceae family which is widely cultivated and grows in the tropical region of the world. ${ }^{24}$

The aim of the present study was to establish a worthy route for the synthesis of bio-molecules capped magnetic Ag NPs by utilizing Artocarpus heterophyllus leaf extract and subsequently, to evaluate their application feasibility against both Grampositive and Gram-negative bacteria. It is notable that Staphylococcus aureus and Bacillus cereus were chosen as the Grampositive bacteria and Escherichia coli and Salmonella typhimurium as the Gram-negative bacteria. Staphylococcus aureus is a pathogenic microorganism which usually colonizes in the axillae, groin, and gastrointestinal tract. ${ }^{25}$ Bacillus cereus causes both gastrointestinal and non-gastrointestinal infections. ${ }^{26}$ Escherichia coli is the best biological indicator of drinking water and is widely used in bacterial studies. It is abundant on mammals' body surfaces and often creates an acute infection. ${ }^{27}$ Salmonella typhimurium causes intestinal disease in humans and numerous hosts. ${ }^{28}$ To the best of our knowledge, this is the first report regarding the synthesis of bio-molecules encapsulated magnetic Ag NPs using Artocarpus heterophyllus leaf extract in view to applying against human pathogens.

\section{Experimental}

\section{Materials}

Artocarpus heterophyllus (jackfruit) leaves were collected locally. Silver nitrate $\left(\mathrm{AgNO}_{3}\right)$ was purchased from Wako Pure Chemical Company, Japan. Bactotrypton, bacto agar and yeast extract were purchased from Difco Laboratories (Detroit, MI, USA). All other reagents and chemicals used in this study were of analytical grade.

\section{Preparation of Artocarpus heterophyllus leaf extract}

Fresh and healthy Artocarpus heterophyllus leaves were washed with tap water following with distilled water to remove unwanted debris. The clean leaves were dried in an oven at $60{ }^{\circ} \mathrm{C}$ and then crushed as leaf powder using a juice blender. $5 \mathrm{~g}$ of leaf powder was added to $100 \mathrm{~mL}$ of deionized water (resistivity $>18 \mathrm{M} \Omega \mathrm{cm}$ ) and then boiled at $80{ }^{\circ} \mathrm{C}$ for 10 minutes. The solution was then filtered. The filtrate here termed as Artocarpus heterophyllus leaf extract was stored at $4{ }^{\circ} \mathrm{C}$ to carry out the conceived experiments.

\section{Synthesis of silver nanoparticles (Ag NPs)}

Ag NPs were synthesized following the procedure published earlier with some modifications. ${ }^{29}$ In brief, $20 \mathrm{~mL}$ of Artocarpus heterophyllus leaf extract was added dropwise into $80 \mathrm{~mL}$ of $1 \mathrm{mM} \mathrm{AgNO}$ solution and mixed through constant magnetic stirring. The mixture was then heated at $60{ }^{\circ} \mathrm{C}$ on a hotplate until the color of the mixture changed from yellow to grey (around $1 \mathrm{~h}$ ). After cooling the mixture at room temperature (30 ${ }^{\circ} \mathrm{C}$ ), a colloidal suspension was obtained. This suspension was centrifuged at $4000 \mathrm{rpm}$ for 10 minutes. As a result, a pellet was obtained which was washed with deionized water repeatedly to remove the impurities and unreacted components. After that, the pellet was collected, dried at $60{ }^{\circ} \mathrm{C}$ in an oven and finally preserved in a desiccator for various analyses. The schematic description of the synthesis procedure of Ag NPs using Artocarpus heterophyllus leaf extract is shown in Fig. 1.

\section{Characterization of the synthesized silver nanoparticles (Ag NPs)}

Various analytical techniques such as UV-Vis spectrometry, energy dispersive X-ray (EDX) spectrometry, field emission scanning electron microscopy (FESEM), transmission electron microscopy (TEM), and X-ray diffraction (XRD) analyses were carried out to understand the successful generation of Ag NPs, their substantial existence, elemental composition, surface morphology, and crystalline phase.

To find out the presence of functional groups in the Artocarpus heterophyllus leaf extract as well as in the expected Ag NPs, Fourier transform infrared (FT-IR) studies were carried out. To evaluate the thermal stability and the content of the residual mass in the $\mathrm{Ag}$ NPs, thermogravimetric analysis (TGA) was carried out. To realize

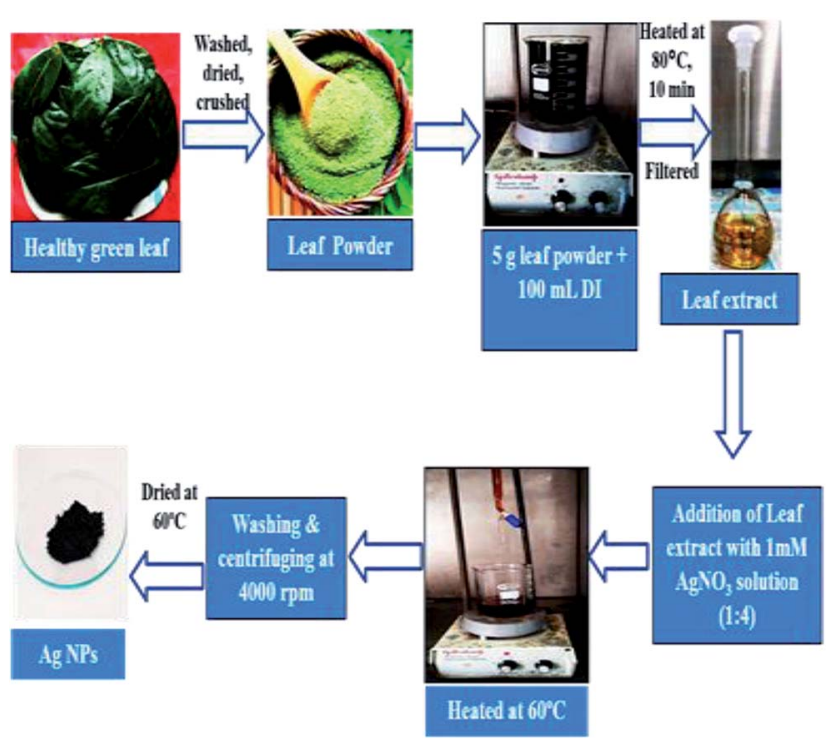

Fig. 1 Schematic diagram of the synthesis of Ag NPs. 
the magnetic property of the Ag NPs, a study using vibrating sample magnetometer (VSM) was carried out.

\section{Adopted analytical techniques and instruments}

The UV-Vis spectrum of the achieved colloidal suspension was recorded using a UV-Vis spectrophotometer (Shimadzu-1800, Japan) at wavelengths ranging from 300-600 $\mathrm{nm}$. Deionized water was used as a blank to adjust the baseline. EDX analysis was performed by JEOL, JSM $7600 \mathrm{~F}$, Japan, using an acceleration voltage of $15 \mathrm{kV}$ and an emission current of $12 \mu \mathrm{A}$. FESEM was carried out by JEOL, model JSM $7600 \mathrm{~F}$, Japan, applying an acceleration voltage of $15 \mathrm{kV}$ and an emission current of $12 \mu \mathrm{A}$. TEM analysis was performed using JEOL, JEM 2010, Japan. The sample for the TEM study was prepared in such a way that at first, a suspension of Ag NPs in 95\% ethanol was prepared in a beaker. The suspension was then sonicated for a period of 5 minutes to obtain a homogeneous mixture. Then $1 \mu \mathrm{L}$ of the suspension was poured on a holey carbon-coated copper grid and dried in air at room temperature. The sample was then placed in the TEM specimen holder and the image was recorded at an accelerating voltage of $120 \mathrm{kV}$. XRD analysis was carried out using an X-ray powder diffractometer (Philips PANalytical X'PERT PRO) equipped with $\mathrm{CuK} \alpha$ radiation (1.5418 $\AA$ ). The spectra were recorded at a voltage of $40 \mathrm{KeV}$ and a current of 30 mA.

FT-IR spectra were recorded using JASCO-FTIR-6300, Japan, at wavenumbers ranging from 500 to $4000 \mathrm{~cm}^{-1}$. In this case, $1 \%(\mathrm{w} / \mathrm{w})$ samples were mixed with $\mathrm{KBr}$ powder and put into a sheer slice. $\mathrm{KBr}$ was used to adjust the baseline. TGA was carried out under $\mathrm{N}_{2}$ atmosphere using TA instrument, SDR Q600 , operating from 25 to $800{ }^{\circ} \mathrm{C}$ at a heating rate of $10{ }^{\circ} \mathrm{C} \mathrm{min}^{-1}$. The magnetic properties of the Ag NPs were evaluated using a vibrating sample magnetometer (EV-9 MicroSense, German). In this study, the first step was the construction of a vibrating mechanism which could vibrate the sample with measurable and controllable amplitude. In the final step, the detection coils detected the magnetic field perturbations produced by vibrating the Ag NPs in the applied magnetic field.

\section{Procedure adopted to assess the antibacterial activity of Ag NPs}

The antibacterial activity of the synthesized Ag NPs was assessed following the disc diffusion method. Four varieties of bacteria - Staphylococcus aureus (ATCC 12228), Bacillus cereus (ATCC 14579), Escherichia coli (ATCC 25922), and Salmonella typhimurium (ATCC 14028) - were taken to assess the antibacterial potentiality of the Ag NPs. The bacteria were cultured in Luria Broth medium (tryptone $1.5 \%$, yeast extract $0.75 \%$, sodium chloride $1.2 \%$ ) at $37{ }^{\circ} \mathrm{C}$ with a $60 \mathrm{rpm}$ shaking water bath. $^{23}$ To measure the zones of inhibition, $15 \mathrm{~mL}$ of $\mathrm{LB}$ medium was poured into a $15 \mathrm{~mm}$ sized Petri plate, after cooling down, $50 \mu \mathrm{L}$ of medium containing bacteria was poured on the Petri plate and smoothly smeared with a glass rod. $7 \mathrm{~mm}$ sized sterilized filter papers were soaked with $15 \mu \mathrm{L}$ of Ag NPs suspensions and placed on culture plates for $24 \mathrm{~h}$. Deionized water disc and leaf extract disc were used as the control.

\section{Results and discussion}

Fig. 2a shows the UV-Vis spectrum of the colloidal solution obtained from the reaction mixture of the $\mathrm{AgNO}_{3}$ solution and Artocarpus heterophyllus leaf extract. A strong absorption peak with peak maxima at $435 \mathrm{~nm}$ appeared in the spectrum. No absorption peak appeared for the aqueous solution of $\mathrm{AgNO}_{3}{ }^{29}$ This result indicates that the prepared colloidal solution (Fig. 2a inset-III) was an optically active material. This optically active material could be speculated to be Ag NPs. It was reported that the optical properties of the Ag NPs enable them to interact strongly with light of a specific wavelength. ${ }^{30}$ Recently, it has been reported that Ag NPs show UV-Vis absorbance maxima at a wavelength between $400-500 \mathrm{~nm}$ due to the surface plasmon resonance. ${ }^{31}$ The results of the UV-Vis spectrum of our studied material show good agreement with the optical nature of the reported Ag NPs. ${ }^{30,31}$ So, it can be concluded that Ag NPs were synthesized through the reaction of $\mathrm{AgNO}_{3}$ solution and Artocarpus heterophyllus leaf extract and the color change from yellow to grey might be due to the reduction of the $\mathrm{Ag}^{+}$ion to $\mathrm{Ag}^{0}$, which correlates with the excitation of the surface plasmon resonance vibration that occurred in the Ag NPs. ${ }^{32}$

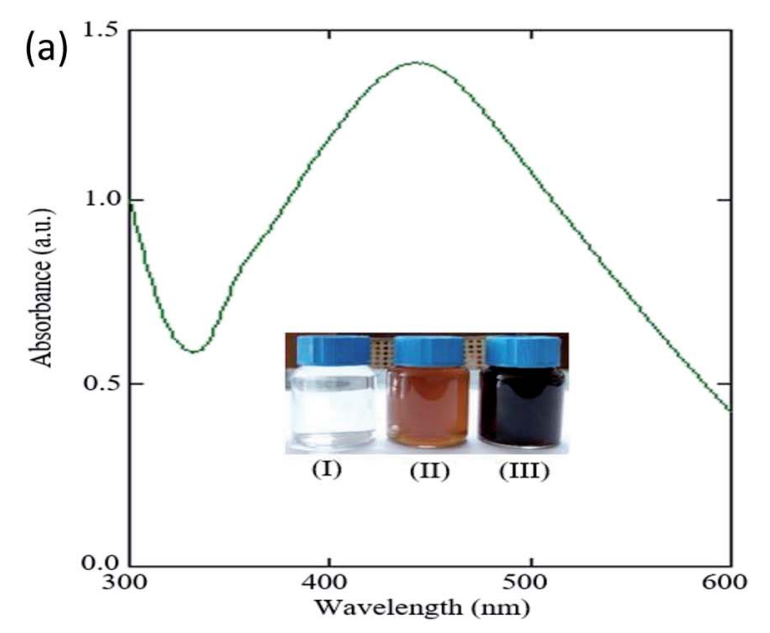

(b)

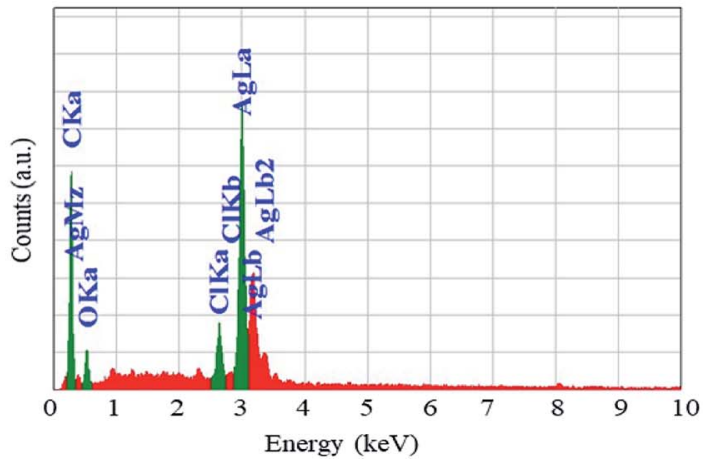

Fig. 2 (a) UV-Vis spectrum of Ag NPs produced by the reduction of $\mathrm{AgNO}_{3}$ solution (1 mM) with Artocarpus heterophyllus leaf extract; inset shows the colors of: (i) the aqueous solution of $\mathrm{AgNO}_{3}$, (ii) Artocarpus heterophyllus leaf extract, and (iii) the colloidal solution, respectively. (b) EDX image showing the presence of Ag NPs and bioorganic components of Artocarpus heterophyllus leaf extract. 
Fig. $2 b$ shows the EDX spectra obtained for the Ag NPs. It is observed that a major peak appeared in the spectra at around 3 $\mathrm{keV}$ which indicates the presence of $\mathrm{Ag}$ in the synthesized materials. ${ }^{33}$ Some weaker peaks also appeared in the spectra which indicate the presence of carbon, oxygen, and chlorine. These elements obviously originated from the leaf extract and indicate their conjunction with the synthesized $\mathrm{Ag}$ NPs. However, it was difficult to understand from this measurement whether 100 percent of these elements acted as the capping agents of the Ag NPs.

The FT-IR spectra obtained for the Artocarpus heterophyllus leaf powder and the synthesized Ag NPs between wavenumbers of $500-4000 \mathrm{~cm}^{-1}$ are shown in Fig. 3a. Three strong peaks appeared in the spectrum obtained for Artocarpus heterophyllus leaf powder at the wavenumber values of 1095, 1631, and $3452 \mathrm{~cm}^{-1}$. These peaks represent the stretching vibration bands of $\mathrm{C}-\mathrm{O}-\mathrm{C},-\mathrm{C}=\mathrm{O}$, and $-\mathrm{OH}$, respectively. ${ }^{32}$ Some weak peaks were also found at the values of 661, 1375, 2852, and $2926 \mathrm{~cm}^{-1}$. These peaks indicate the stretching vibration bands of $\mathrm{C}-\mathrm{Cl}$, the $\mathrm{C}-\mathrm{N}$ of the amine, $\mathrm{N}-\mathrm{H}$, and $\mathrm{C}-\mathrm{H}$, respectively. ${ }^{29}$ Four strong peaks appeared for the leaf extract-mediated synthesized Ag NPs at the wavenumber values of 1099, 1382, 1631 , and $3464 \mathrm{~cm}^{-1}$ which represent the stretching vibration bands of $\mathrm{C}-\mathrm{O}-\mathrm{C}$, the $\mathrm{C}-\mathrm{N}$ of the amine, $-\mathrm{C}=\mathrm{O}$, and $-\mathrm{OH}$, respectively. ${ }^{29,32}$ Weak peaks appeared at 669, 2870, and
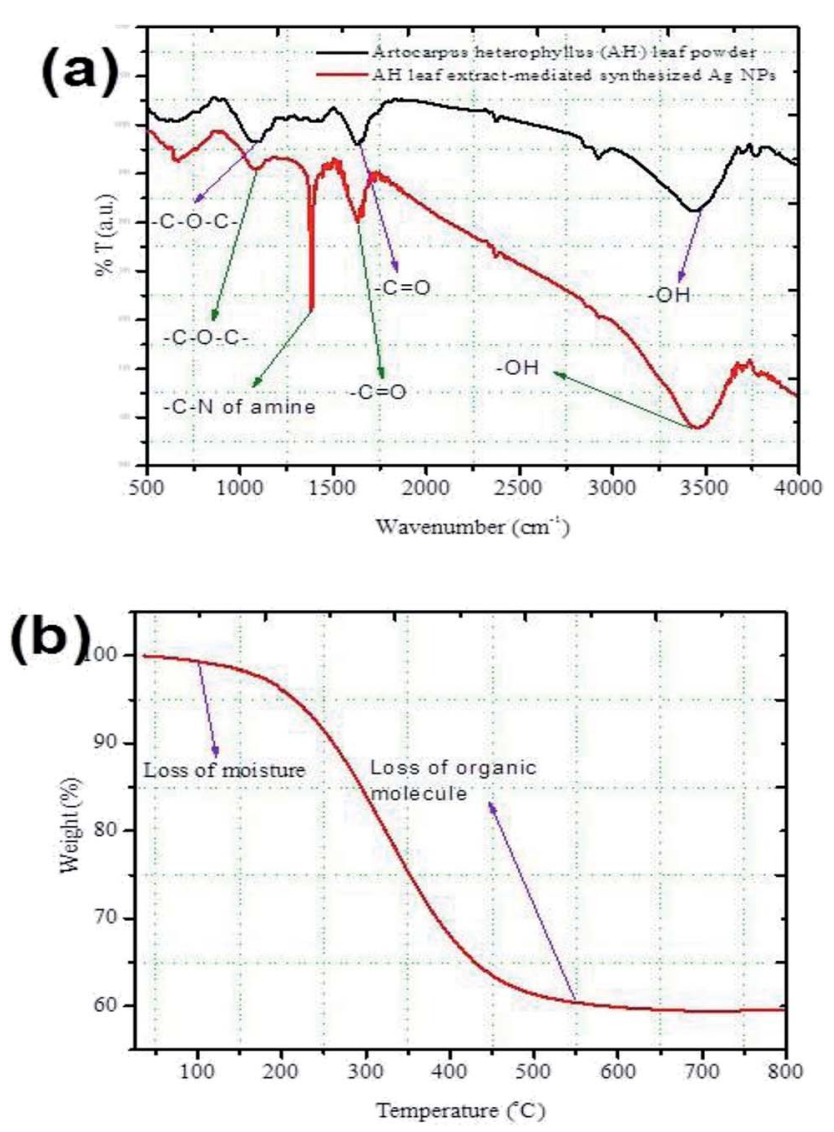

Fig. 3 (a) FT-IR spectra of Artocarpus heterophyllus (AH) leaf powder and $A H$ leaf extract mediated synthesized Ag NPs. (b) TGA plot for assynthesized Ag NPs synthesized using Artocarpus heterophyllus leaf extract and $\mathrm{AgNO}_{3}$ solution.
$2954 \mathrm{~cm}^{-1}$ indicating the stretching vibration bands of $\mathrm{C}-\mathrm{Cl}, \mathrm{N}-$ $\mathrm{H}$, and $\mathrm{C}-\mathrm{H}$, respectively. ${ }^{9}$

Fig. 3a demonstrates that similar functional groups existed both in the leaf powder and the synthesized Ag NPs but they showed dissimilarities in their band intensities. It is important to note that a new peak appeared corresponding to the $\mathrm{C}-\mathrm{N}$ of the amine for the leaf extract-mediated synthesized $\mathrm{Ag}$ NPs. This observation can conclude that the $\mathrm{C}-\mathrm{N}$ of the amine behaved as a major capping agent and it was responsible for enhancing the stability of the synthesized Ag-NPs. Although, some authors ${ }^{31}$ have claimed that $-\mathrm{OH}$ and $-\mathrm{NH}$ from leaf extract could act as reducing agents and were capable of reducing $\mathrm{Ag}^{+}$ions to the metallic silver nanoparticles, i.e., nano $\mathrm{Ag}^{\mathrm{O}}$ in ambient conditions. On the other hand, heterocyclic compounds like alkaloid, flavones, and anthracenes have also acted as the capping agent of NPs. ${ }^{32}$

Fig. $3 \mathrm{~b}$ shows the TGA plot obtained for the synthesized Ag NPs. It was found that the weight loss of the sample was about $1.5 \%$ at $100{ }^{\circ} \mathrm{C}$ which might be due to the weight of moisture present in the Ag NPs. With increasing temperature, a sharp weight loss started which continued up to around $550{ }^{\circ} \mathrm{C}$. At this stage, the weight loss was around $40 \%$ which might be due to the loss of organic molecules existing with the Ag NPs. Above $550{ }^{\circ} \mathrm{C}$, the weight loss was negligible. The residual weight was about $58 \%$ and it could be the net weight of $\mathrm{Ag}$ present in the sample. Thus, it can be concluded that the presence of almost $40 \%$ organic molecules in the Artocarpus heterophyllus leaf extract mediated synthesized Ag NPs might be acting as a capping agent.

The FESEM image (Fig. 4a) shows that NPs were dispersed over the surface by preserving a relative uniformity and appeared to be less agglomerated. The minimal aggregation of the Ag NPs might be due to the encapsulation of Ag NPs with bio-molecules. The synthesis process of Artocarpus heterophyllus leaf extract mediated Ag NPs was repeated three times and the surface morphology of the particles was found to be reproducible. Thus, FESEM analysis depicts the potentiality of Artocarpus heterophyllus leaf extract to minimize the aggregation of Ag NPs.

The TEM image (Fig. 4b) demonstrates that the Ag NPs were nearly spherical shaped with below $15 \mathrm{~nm}$ size. An intense look at the NPs elucidates that they were mostly encapsulated with a thick layer of organic molecules which emphasized the achievement of one of the goals of the present study, i.e., the attempt of encapsulation of Ag NPs by organic molecules.

The Rietveld refinement of the obtained XRD pattern of the synthesized $\mathrm{Ag}$ NPs is shown in Fig. 5. Five diffraction peaks appeared at the $2 \theta$ values of $38.11^{\circ}, 44.33^{\circ}, 64.35^{\circ}, 77.62^{\circ}$, and $82.33^{\circ}$ which correspond to the $(\mathrm{Ag})_{111},(\mathrm{Ag})_{200},(\mathrm{Ag})_{220},(\mathrm{Ag})_{311}$, and $(\mathrm{Ag})_{222}$ planes, respectively. Diffraction peaks obtained in XRD ensured a face centre cubic structure with the $F m \overline{3} m$ space group in accordance with the JCPDS card of silver (JCPDS card number 87-0597). The unit cell parameter and unit cell volume of cubic Ag NPs obtained from the Rietveld refinement are $4.09667 \AA$ and $68.753 \AA^{3}$, respectively. According to the refinement, we found a small amount of unknown phase impurities along with the main phase as shown in Fig. 5. The phase identification process showed the absence of all the most 

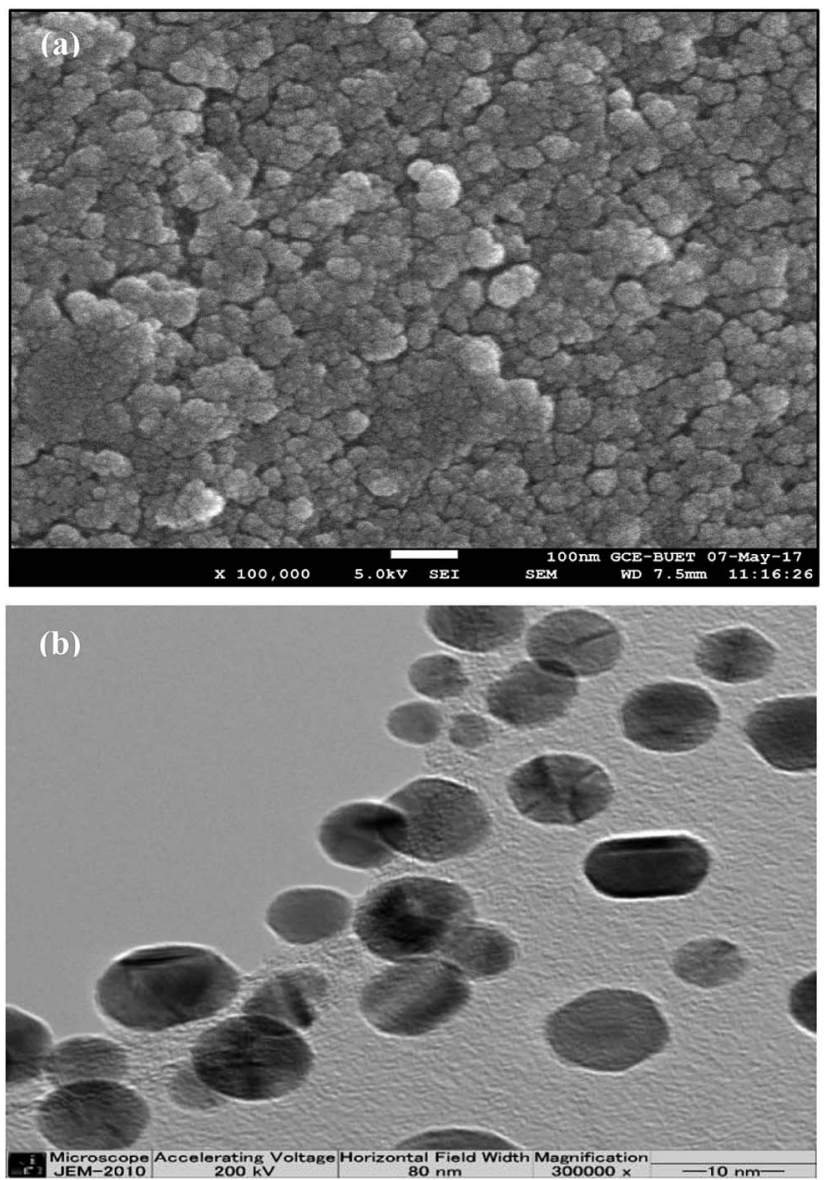

Fig. 4 (a) FESEM image showing the surface morphology of Ag NPs synthesized using Artocarpus heterophyllus ( $\mathrm{AH}$ ) leaf extract and $\mathrm{AgNO}_{3}$ solution. (b) TEM image showing the particle size of encapsulated Ag NPs synthesized using $\mathrm{AH}$ leaf extract and $\mathrm{AgNO}_{3}$ solution.

probable combinations of silver oxide. So, the unknown impurities that appeared might be due to remaining parts of the leaf extraction. Moreover, the obtained XRD pattern is analogous with earlier reported data. ${ }^{34}$ The crystallite size of the achieved $\mathrm{Ag}$ NPs was calculated using the Scherrer approximation ${ }^{35}$ and was found to be $13 \mathrm{~nm}$. This value coincides with the value obtained from the TEM study. The lattice constant was measured using the Nelson-Riley function ${ }^{36}$ and was found to be $4.0911 \AA$, showing a good agreement with the reported value $^{29}$ and Rietveld refinement data.

The magnetization versus the applied field plot for the synthesized Ag NPs is shown in Fig. 6. The hysteresis loop indicates the weak ferromagnetic behaviour of the Ag NPs with a saturation magnetization of $0.085 \mathrm{emu} \mathrm{g}^{-1}$ and coercivity of 149 Oe. The saturation magnetization obtained in the present study shows better magnetization results than the previously reported Ag NPs. ${ }^{37}$ It was predicted that ferromagnetic spin polarization could take place in $4 \mathrm{~d}$ and $5 \mathrm{~d}$ transition metals with reduced coordination geometry because of the large ratio of the number of atoms on the surface to the number in the core. ${ }^{38}$ Consequently, it was speculated that the ferromagnetic nature of the Ag NPs might be due to the spin polarization. Moreover, the weak ferromagnetic nature of the Ag NPs might

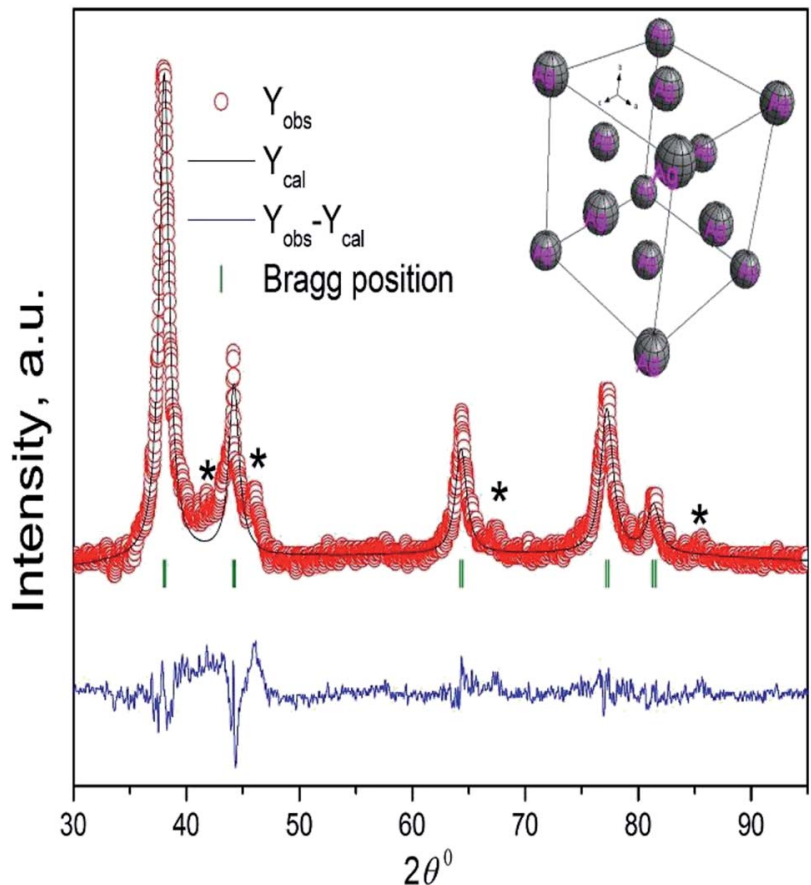

Fig. 5 The Rietveld refinement of the XRD pattern of Ag NPs synthesized using Artocarpus heterophyllus leaf extract and $\mathrm{AgNO}_{3}$ solution. The inset shows the cubic structure of Ag NPs.

be due to the weak coupling between the capping agents and the Ag surface. ${ }^{9}$ The ferromagnetic nature of thiol-capped Ag NPs was reported earlier where the authors claimed that charge transfer occurred from the surface metal to the $\mathrm{S}$ atoms which induced the anisotropic orbital momenta, resulting in the

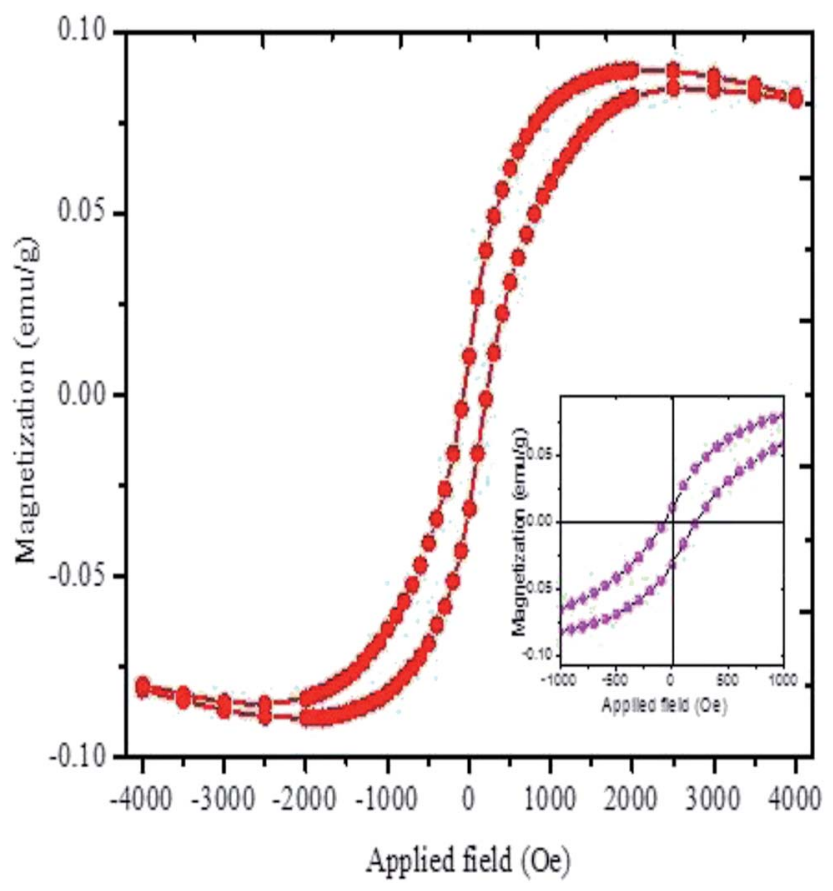

Fig. 6 The magnetization curve of Ag NPs synthesized using Artocarpus heterophyllus leaf extract and $\mathrm{AgNO}_{3}$ solution. The inset shows the enlargement view of the hysteresis loop. 

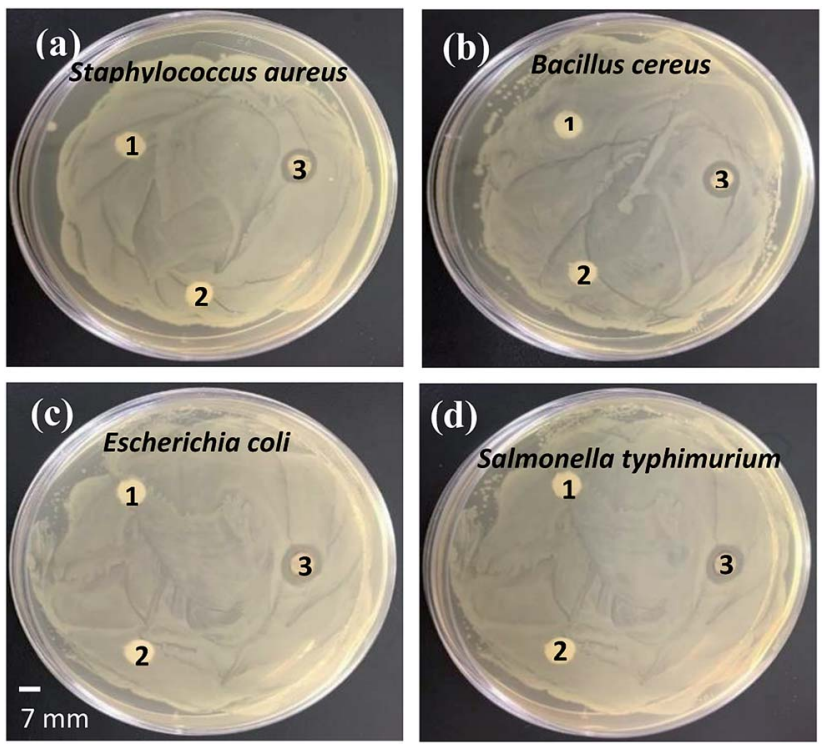

Fig. 7 Antibacterial activity of (1) deionized water, (2) leaf extract and (3) Ag NPs against Gram positive (a) Staphylococcus aureus and (b) Bacillus cereus, and Gram negative (c) Escherichia coli and (d) Salmonella typhimurium pathogenic bacteria.

magnetic nature of the Ag NPs. ${ }^{39}$ Therefore, it is assumed that the $\mathrm{Cl}$ plays a similar role for the weak ferromagnetic nature in the currently studied Ag NPs. Moreover, the presence of a small amount of oxygen in the sample (Fig. 2b) predicting the presence of a non-stoichiometric oxide layer on the surface results in the ferromagnetic nature of Ag NPs. ${ }^{37}$ The ferromagnetic behavior of the synthesized Ag NPs indicates the success of our present study in synthesizing organic molecules capped magnetic Ag NPs using Artocarpus heterophyllus leaf extract and $\mathrm{AgNO}_{3}$ solution.

The antibacterial activity of the synthesized organic molecules capped magnetic Ag NPs was investigated against both the Gram-positive and Gram-negative bacteria using the agar well diffusion assay. Fig. 7 represents the zones of inhibition of the bacteria. The zones of inhibition for Staphylococcus aureus, Bacillus cereus, Escherichia coli, and Salmonella typhimurium bacteria were found to be around 15, 16, 19, and $18 \mathrm{~mm}$, respectively.

The antibacterial activities of the biosynthesized Ag NPs in comparison with the literature are summarized in Table 1 . The observation indicates the efficient antibacterial activity of the synthesized Ag NPs against both the Gram-positive and Gramnegative bacteria. However, the lower zone of inhibition for the Gram-positive bacteria than that of the Gram-negative bacteria could be due to the thicker cell wall of the former than that of latter (Fig. 7). Authors ${ }^{40}$ have reported that Grampositive bacteria are composed of thicker rigid multiple layers of peptidoglycan than Gram-negative bacteria which prevent the NPs from entering the cell wall. In contrast, the negative control (deionized water and leaf extract) did not show any zones of inhibition against all the four investigated human

Table 1 Various biosynthesized Ag NPs induced zones of inhibition against pathogenic bacteria

\begin{tabular}{|c|c|c|c|c|c|}
\hline Pathogenic bacteria & Extracted substances & $\begin{array}{l}\text { Size of Ag } \\
\text { NPs (nm) }\end{array}$ & $\begin{array}{l}\text { Concentration } \\
\text { of } \mathrm{Ag} \text { NPs }\left(\mathrm{mg} \mathrm{L}^{-1}\right)\end{array}$ & $\begin{array}{l}\text { Zones of } \\
\text { inhibition }(\mathrm{mm})\end{array}$ & Reference \\
\hline \multirow[t]{5}{*}{ Staphylococcus aureus } & Phlomis & $19-30$ & 100 & 14.7 & 40 \\
\hline & Eriobotrya japonica & $20-50$ & 100 & 4.5 & 42 \\
\hline & Lepidium draba & $20-80$ & 100 & 10.8 & 43 \\
\hline & Aloe vera & $10-30$ & 50 & 18.1 & 44 \\
\hline & Artocarpus heterophyllus & 13-15 & 100 & 15 & Present work \\
\hline \multirow[t]{5}{*}{ Escherichia coli } & Phlomis & $19-30$ & 100 & 15.1 & 40 \\
\hline & Helicteres isor & $16-95$ & 100 & 4 & 41 \\
\hline & Melissa officinalis & 12 & 100 & 5 & 45 \\
\hline & Ocimum Sanctum & $10-20$ & 150 & 14 & 46 \\
\hline & Eriobotrya japonica & 19.75 & 100 & 2.5 & 42 \\
\hline & Lepidium draba & $20-80$ & 100 & 10.4 & 43 \\
\hline & Aloe vera & $10-30$ & 50 & 6.3 & 44 \\
\hline & Portulaca oleracea & $15-40$ & & 5.5 & \\
\hline & Cynodon dactylon & $25-60$ & & 6.0 & \\
\hline & Artocarpus heterophyllus & 13-15 & 100 & 18 & Present work \\
\hline \multirow[t]{6}{*}{ Bacillus cereus } & Phlomis & $19-30$ & 100 & 12.1 & 40 \\
\hline & Lepidium draba & $20-80$ & 100 & 10.8 & 43 \\
\hline & Aloe vera & $10-30$ & 50 & 11.4 & 44 \\
\hline & Portulaca oleracea & $15-40$ & & 9.4 & \\
\hline & Cynodon dactylon & $25-60$ & & 12.7 & \\
\hline & Artocarpus heterophyllus & 13-15 & 100 & 16 & Present work \\
\hline
\end{tabular}


pathogens. The exact mechanism(s) of the antibacterial activity of the Ag NPs against various pathogenic bacteria is still unclear and requires further investigation. ${ }^{47,48}$ However, it is known that NPs are capable of penetrating bacterial cells and acting as a catalyst to inactivate enzymes by interacting with the thiol groups of proteins that microorganisms need for their metabolism. Thus, NPs could disturb bacterial membranes and affect their DNA replication. ${ }^{\mathbf{4 9 , 5 0}}$

\section{Conclusions}

In the present study, we showed the green synthesis of stable silver nanoparticles (Ag NPs) using Artocarpus heterophyllus leaf extract as a reducing and capping agent, which is ferromagnetic in nature. The synthesis method is simple, fast, cost-effective, eco-friendly, and efficient, which excludes external reducing agents and stabilizers. The formation of magnetic Ag NPs was confirmed from the UV-Vis, EDX, FT-IR, XRD, FESEM, TEM, TGA and VSM analyses. An absorbance peak with peak maxima at $435 \mathrm{~nm}$ appeared in the UV-Vis spectrum for the synthesized $\mathrm{Ag}$ NPs. The crystallinity was examined by XRD techniques and found to be a face centered cubic (fcc) structure with an average crystallite size of $13 \mathrm{~nm}$. A small hysteresis loop was obtained from the VSM analysis indicating the weak ferromagnetic nature of the biosynthesized Ag NPs. The synthesized Ag NPs showed potential antibacterial activity against both the Grampositive and Gram-negative bacteria. Ferromagnetic Ag NPs achieved from the Artocarpus heterophyllus leaf extract mediated green synthesis have immense potential and might have a notable impact on the pharmaceutical, biomedical, and cosmetic industries. Moreover, these Ag NPs could become an alternative to chemically synthesized Ag NPs.

\section{Conflicts of interest}

There are no conflicts of interest to declare.

\section{Notes and references}

1 S. Maiti, D. Krishnan, G. Barman, S. K. Ghosh and J. K. Laha, J. Anal. Sci. Technol., 2014, 5, 40.

2 D. V. Parikh, T. Fink, K. Rajasekharan, N. D. Sachinvala, A. P. S. Sawhney, T. A. Calamari and A. D. Parikh, Text. Res. J., 2005, 75, 134-138.

3 M. Akter, M. T. Sikder, M. M. Rahman, A. K. M. A. Ullah, K. F. B. Hossain and M. Kurasaki, J. Adv. Res., 2018, 9, 1-16. 4 Q. Sun, X. Cai, J. Li, M. Zheng, Z. Chen and C.-P. Yu, Colloids Surf., A, 2014, 444, 226-231.

5 I. Diez and R. H. A. Ras, Nanoscale, 2011, 3, 1963-1970.

6 H. Gu, P.-L. Ho, K. W. T. Tsang, L. Wang and B. Xu, J. Am. Chem. Soc., 2003, 125, 15702-15703.

7 F. Cheng, J. W. Betts, S. M. Kelly, J. Schaller and T. Heinze, Green Chem., 2013, 15, 989-998.

8 J. He, T. Kunitake and A. Nakao, Chem. Mater., 2003, 15, 4401-4406.
9 Y. Yamamoto, T. Miura, M. Suzuki, N. Kawamura, H. Miyagawa, T. Nakamura, K. Kobayashi, T. Teranishi and H. Hori, Phys. Rev. Lett., 2004, 93, 116801.

10 P. Crespo, R. Litran, T. C. Rojas, M. Multigner, J. M. Fuente, J. C. Sanchez-Lopez, M. A. Garcia, A. Hernando, S. Penades and A. Fernandez, Phys. Rev. Lett., 2004, 93, 087204.

11 M. Dubey, S. Bhadauria and B. S. Kushwah, Dig. J. Nanomater. Biostruct., 2009, 4, 537-543.

12 V. Kumar, S. C. Yadav and S. K. Yadav, J. Chem. Technol. Biotechnol., 2010, 85, 1301-1309.

13 A. Nabikhan, K. Kandasamy, A. Raj and N. M. Alikunhi, Colloids Surf., B, 2010, 79, 488-493.

14 S. Ankanna, T. N. V. K. V. Prasada, E. K. Elumalai and N. Savithramma, Dig. J. Nanomater. Biostruct., 2010, 5, 369372.

15 S. A. Babu and H. G. Prabu, Mater. Lett., 2011, 65, 1675-1677. 16 A. Bankar, B. Joshi, A. R. Kumar and S. Zinjarde, Colloids Surf., A, 2010, 368, 58-63.

17 C. Krishnaraj, E. G. Jagan, S. Rajasekar, P. Selvakumar, P. T. Kalaichelvan and N. Mohan, Colloids Surf., B, 2010, 76, 50-56.

18 M. Sathishkumar, K. Sneha, S. W. Won, C.-W. Cho, S. Kim and Y.-S. Yun, Colloids Surf., B, 2009, 73, 332-338.

19 V. N. Sonkusare, R. G. Chaudhary, G. S. Bhusari, A. R. Rai and H. D. Juneja, Nano-Struct. Nano-Objects, 2018, 13, 121131.

20 S. Yallappa, D. R. Deepthi, S. Yashaswini, R. Hamsanandini, M. Chandraprasad, S. A. Kumar and G. Hegde, Nano-Struct. Nano-Objects, 2018, 12, 84-90.

21 A. Anas, J. Jiya, M. J. Rameez, P. B. Anand, M. R. Anantharaman and S. Nair, Lett. Appl. Microbiol., 2012, 56, 57-62.

22 S. I. Sadovnikov, Y. V. Kuznetsova and A. A. Rempel, NanoStruct. Nano-Objects, 2016, 7, 81-91.

23 O. Prakash, R. Kumar, A. Mishra and R. Gupta, Pharmacogn. Rev., 2009, 3, 353-358.

24 M. S. Baliga, A. R. Shivashankara, R. Haniadka, J. Dsouza and H. P. Bhat, Food Res. Int., 2011, 44, 1800-1811.

25 H. F. L. Wertheim, D. C. Melles, M. C. Vos, W. Leeuwen, A. Belkum, H. A. Verbrugh and J. Nouwen, Lancet Infect. Dis., 2005, 5, 751-762.

26 A. Kotiranta, K. Lounatmaa and M. Haapasalo, Microbes Infect., 2000, 2, 189-198.

27 S. C. Edberg, E. W. Rice, R. J. Karlin and M. J. Allen, Symp. Ser. - Soc. Appl. Microbiol., 2000, 29, 106S-116S.

28 A. Fàbrega and J. Vila, Clin. Microbiol. Rev., 2013, 26, 308341.

29 M. Akter, M. M. Rahman, A. K. M. A. Ullah, M. T. Sikder, T. Hosokawa, T. Saito and M. Kurasaki, J. Inorg. Organomet. Polym. Mater., 2018, 28, 1483-1493.

30 X.-F. Zhang, Z.-G. Liu, W. Shen and S. Gurunathan, Int. J. Mol. Sci., 2016, 17, 1534.

31 J. M. Ashraf, M. A. Ansari, H. M. Khan, M. A. Alzohairy and I. Choi, Sci. Rep., 2016, 6, 20414.

32 J. Huang, Q. Li, D. Sun, Y. Lu, Y. Su, X. Yang, H. Wang, Y. Wang, W. Shao, N. He, J. Hong and C. Chen, Nanotechnology, 2007, 18, 105104. 
33 D. Sarvamangala, K. Kondala, N. Sivakumar, M. S. Babu and S. Manga, Int. Res. J. Pharm., 2013, 4, 240-243.

34 Y.-H. Hsueh, K.-S. Lin, W.-J. Ke, C.-T. Hsieh, C.-L. Chiang, D.-Y. Tzou and S.-T. Liu, PLoS One, 2015, 10, 0144306.

35 A. K. M. A. Ullah, A. K. M. F. Kibria, M. Akter, M. N. I. Khan, A. R. M. Tareq and S. H. Firoz, Water Conservation Science and Engineering, 2017, 1, 249-256.

36 A. K. M. A. Ullah, A. K. M. F. Kibria, M. Akter, M. N. I. Khan, M. A. Maksud, R. A. Jahan and S. H. Firoz, J. Saudi Chem. Soc., 2017, 21, 830-836.

37 A. J. Marenco, D. B. Pedersen and S. Trudel, J. Mater. Chem. C, 2017, 5, 4899-4908.

38 S. Blügel, Phys. Rev. B: Condens. Matter Mater. Phys., 1995, 51, 2025-2028.

39 J. S. Garitaonandia, M. Insausti, E. Goikolea, M. Suzuki, J. D. Cashion, N. Kawamura, H. Ohsawa, I. Gil de Muro, K. Suzuki, F. Plazaola and T. Rojo, Nano Lett., 2008, 8, 661667.

40 A. R. Allafchian, S. Z. Mirahmadi-Zare, S. A. H. Jalali, S. S. Hashemi and M. R. Vahabi, J. Nanostruct. Chem., 2016, 6, 129-135.
41 S. Bhakya, S. Muthukrishnan, M. Sukumaran and M. Muthukumar, Appl. Nanosci., 2016, 6, 755-766.

42 B. Rao and R. C. Tang, Adv. Nat. Sci.: Nanosci. Nanotechnol., 2017, 8(015014), 1-8.

43 F. Benakashani, A. Allafchian and S. A. H. Jalali, Green Chem. Lett. Rev., 2017, 10, 324-330.

44 T. A. Abalkhil, S. A. Alharbi, S. H. Salmen and M. Wainwright, Biotechnol. Biotechnol. Equip., 2017, 31, 411-417.

45 A. D. J. R. Baltazar, S. Y. R. Lopez, D. Larranga, M. Estevez and R. Perez, Results Phys., 2017, 7, 2639-2643.

46 S. Jain and M. S. Mehata, Sci. Rep., 2017, 7, 1-12.

47 M. J. Ahmed, G. Murtaza, A. Mehmood and T. M. Bhatti, Mater. Lett., 2015, 153, 10-13.

48 M. Bindhu and M. Umadevi, Spectrochim. Acta, Part A, 2014, 128, 37-45.

49 G. A. Martinez-Castanon, N. Nino-Martinez, F. MartinezGutierrez, J. R. Martinez-Mendoza and F. Ruiz, J. Nanopart. Res., 2008, 10, 1343-1348.

50 S. J. Klaine, P. J. J. Alvarez, G. E. Batley, T. F. Fernandes, R. D. Handy, D. Y. Lyon, S. Mahendra, M. J. McLaughlin and J. R. Lead, Environ. Toxicol. Chem., 2008, 27, 1825-1851. 